\title{
ON THE CONDUCTIVITY OF THE LATENT IMAGE
}

BY A. G. RABINOVICH

The nature of the latent image, i. e., of the invisible image, which exists in the exposed, but undeveloped photographic plate, is not clear till now. There are many theories ${ }^{1}$ which attempt to reduce it to chemieal or physical changes of the sensitive layer, but no one of them could prevail over the others. The causes of this are: that the latent image can be produced not only by light, but also by other factors, that its character depends both on the sensitive silver halide and on the properties of the gelatine film, in which it is emulsified; but the principal cause is that the amount of silver bromide changed by light, forms such a small part of the whole that it could be detected by no analytical means.

The adherents to the "physical" theories describe the latent image as the alteration only of the physical properties of silver bromide, without chemical decomposition of its molecules: such are Chapman Jones, and Namias, who reduce it to polymerization; Hurter and Driffield on the contrary - to depolymerization; DeHeen ${ }^{2}$ - to ionization (without separation of ions) etc.

The adepts of the "chemical" theories believe that the formation of the latent image consists in the reduction of $\mathrm{AgBr}$, the particles of which are decomposed under the action of light. Abegg and Ostwald suppose that a part of the molecules of $\mathrm{AgBr}$ are reduced to metallic silver, forming each a "nucleus" or germ around which further quantities of silver are deposited during the developing process.

The upholders of the "subhalide" theory, which predominated at a certain time (Eder, Luther, Baur, Schaum, Trivelli and others) believe that silver bromide is reduced not to silver,

1 For the bibliography see W. D. Bancroft: Jour. Phys. Chem., 15, 313, 551 (1911); 16, 29, 89 (1912); 17, 93 (1913).

${ }^{2}$ De Heen: Bull. Ac. roy. Belg. sc., 1910, 546. 
but to a compound containing less halogen than $\mathrm{AgBr}$, a "subhalide," as $\mathrm{Ag}_{2} \mathrm{Br}$.

After Carey Lea's discovery of colloidal silver in many coloured modifications and of photohalides a new "adsorption" theory arose, taking the latent image for silver bromide which has adsorbed the subhalide. Later another theory ( $R$. Lorenz, Lüppo-Cramer, W. Bancroft, Reinders and others) has been put forward, where the adsorbed substance is supposed to be colloidal silver.

The partisans of the old theories have not all been convinced by the arguments of the supporters of the new one, and polemics on the pages of photographic and general scientific journals continue till today.

The elucidation of the nature of the latent image may be advanced by the investigation of its physical properties. Many of them are known. Yet, there is no sufficient experimental material on the important question about the possible change of the electrical conductivity of the photographic plate after insolation, i. e., how the formation of the latent image does influence the conductivity of the plate. This question was investigated by $\mathrm{H}$. Meyer, ${ }^{1}$ but only in application to the chromated gelatine, where the process is of course different from that in the bromogelatine silver emulsion. The resistance of the last (in the wet state only) has been measured by Novàk ${ }^{2}$ by means of alternating current wire bridge and a sensitive dynamometer. He has found that when a wet plate is exposed to the light of an Auer burner its resistance decreases at once very little, then increases during an hour to $1 \%$, then diminishes again, falling to a value lower than before the experiment. In this work the effect of the heating by the source of light has not been measured, the exposure was much longer than usual and gave not a normal image, but rather an effect of solarization. Therefore the work of Novàk does not give 66. 48 (1909).

${ }^{1}$ H. Meyer: Zeit. wiss. Photogr., Photoch., 8, 1 (1910); Zeit. phys. Chem.,

${ }^{2}$ V. Novàk: Sitzungsber. Rgl. Böhm. Ges. Wiss., 1902, 41 (with a brief English summary). 
a clear reply to the question, how the conductivity of the layer changes when a latent image be formed in it.

On the other side, however, there are many papers stating the influence of light on the conductivity of individual (pure) substances. Such are first the numerous works describing the well-known properties of selenium. Later the same property (increase of the conductivity under the influence of light) in the less pronounced manner has been found in some other substances, especially of mineral origin, e. g., the compounds of sulfur, arsenic, etc., with heavy metals. ${ }^{1}$ Arrhenius $^{2}$ has shown that the conductivity of thin films of halide silver salts increases in all parts of the visible spectrum approximately in proportion to the (photometric) intensity of the light. The maximum of the light action was observed on the boundary between the visible and the ultra-violet parts of the spectrum. When the salts have been impregnated with optical sensitizers, the maximum of the light action migrated to the maximum of light absorption of the given sensitizer. Rudert ${ }^{3}$ also found a decrease of resistance of cuprous iodide under the influence of light. Scholl ${ }^{4}$ exposed thin membranes of silver iodide to the light of an arc lamp, which made their conductivity 40-50 times larger than before. From the diffusion, he calculated the velocity of migration of the electricity bearers and found it to exceed many times all known ionic velocities. He concluded from this that the bearers of electricity, which appear in the $\mathrm{Ag}$ under the action of light, are free electrons. W. Wilson ${ }^{5}$ has studied the photoelectric effect in AgI by another method: in front of the plate of silver iodide exposed to the influence of light he placed a copper plate which caught the electrons emitted by AgI, and the quantity of electricity brought away by them was measured by a special device.

${ }_{1}^{1}$ Pfund: Phys. Rev., 7, 298 (1916); T. W. Case, Phys. Rev., 9, 305

(1917); Martin: Phys. Zeit., 12, 41 (1911).

2 Arrhenius: Sitzungsber. Akad. Wiss:, Wien, 96, 831 (1887).

${ }^{3}$ Rudert: Ann. Phys., (4) 31, 559 (1910).

${ }^{4}$ Scholl: Zeit. wiss. Photogr., 4, 1 (1906).

${ }^{5}$ W. Wilson: Ann. Phys., (4) 23, 107 (1907). 
All these works suggested the idea that the galvanic resistance of the light-sensitive layer of the photographic plate might decrease under the influence of light, and that the appearance of the latent image could be reduced to a purely physical phenomenon-the increase of the number of free electrons (in parts of the plate exposed to light). For the definitive resolution of this question the change of conductivity of the sensitive emulsion under the influence of light had to be studied experimentally. The present work was undertaken for this purpose.

The resistance was measured by means of a method proposed by W. Siemens ${ }^{1}$ developed by H. Meyer ${ }^{2}$ and carefully studied by us. ${ }^{3}$ This method allowing the measuring of enormous resistances by means of instruments of relatively low sensitivity, consists in charging a condenser through the resistance under test during a given time and in the following discharge of the same condenser through a ballistic galvanometer. In the course of improvement of this method principal weight had to be laid on the elimination of the sources of accidental irregularities as e. g., thermo-currents from the hands of the observer; residual charge of the condenser, polarization of the resistance, dissymmetry of deflections, inconstancy of contacts, etc. After the removal of all these causes of errors the method allowed to measure resistances of about $10^{9}-10^{10} \mathrm{ohm}$ with an accuracy of $0.5-1.0 \%$.

As the glass plate bearing the layer presented too high a conductance, light-sensitive films were studied where the conductivity of the celluloid film is only one-twentieth of that of the layer. Contacts consisted of tin-foil and Hofman's chemical clips. To exclude the conductance by the gelatine layer covering the back-side of certain films it was isolated from tin-foil by thin ebonite plates. The electrical conductivity of such a film "Premo" Kodak I,td. of the size $5 \times 10 \mathrm{~mm}$. at $18^{\circ}-20^{\circ} \mathrm{C}$ was of the order of magnitude $10^{-11} \mathrm{ohm}^{-1} \mathrm{~cm}^{-1}$.

${ }^{1} \mathrm{~W}$. Siemens: Wissenschaftliche und technische Arbeiten, 1, 137 (1889).

${ }^{2} \mathrm{H}$. Meyer: loc. cit.

${ }^{3}$ It will be described in another paper. 
The first experiments showed that this value depends in a high degree on the temperature and on the hygrometric state of the atmosphere. To protect the film from these external influences and from light, we placed it with the contacts in a black wooden box with a glass window which could be closed tightly by a card-board cover pasted over with black velvet. Two wires entered this box through paraffin and ebonite insulators and were connected with the contacts by means of the above-mentioned clips. A thermometer divided into fifths of a degree and allowing fiftieths to be read was introduced into the same box. As the exposure to light always heated the film the temperature coefficient of its electrical resistance was measured first. For this purpose the box was heated from outside to $1^{\circ}-2^{\circ}$ by means of a hot-air current from an electrical fan "Foen."

All readings on the thermometer and galvanometer were taken every three minutes. The results are given in Table I and on the one curve (Fig. 1), where values of time in minutes are plotted as abscissae and those of temperature $t$

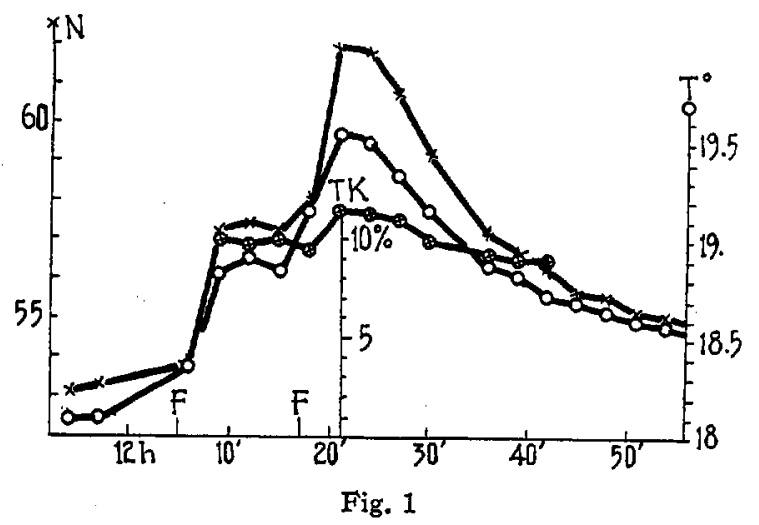

in degrees for the one curve (circles) and those of galvanometer deflections in min on the scale for the other (crosses) are plotted as ordinates. Two short lines with the inscription $F$ show the moments, where heating with the "Foen" has been applied to the whole apparatus. 
TABLE I

\begin{tabular}{c|c|c|c|c}
\hline \hline $\begin{array}{c}\text { Reading } \\
\text { at }\end{array}$ & $\begin{array}{c}\text { Deflection } \\
\mathrm{N}\end{array}$ & $\begin{array}{c}\text { Ternp. t } \\
\text { degree }\end{array}$ & $\begin{array}{c}\text { Mean } \\
\text { temp.t } \\
\text { degree }\end{array}$ & $\begin{array}{c}\text { Mean } \\
\text { temp. } \\
\text { coef. } \\
\text { percent }\end{array}$ \\
\hline $\begin{array}{c}11 \mathrm{~h} .54^{\prime} \\
57^{\prime}\end{array}$ & $\begin{array}{c}+53.1 \\
-53.3\end{array}$ & $-\begin{array}{c}\text { M.t.c } \\
\text { of exp. } \\
\text { percent }\end{array}$ \\
\hline 18.09 & - & - \\
\hline
\end{tabular}

12h. $5^{\prime}$ Heating of the box during $30^{\prime \prime}$ by a hot air current from "Foen"

\begin{tabular}{r|r|r|r|r|r}
$.6^{\prime}$ & +53.8 & $18.18-18.50$ & 18.34 & - & \\
$9^{\prime}$ & -57.2 & $18.80-18.86$ & 18.83 & .10 & 13 \\
$12^{\prime}$ & -57.4 & $18.90-18.90$ & 18.90 & 9.7 & 5.6 \\
$15^{\prime}$ & +57.2 & $18.85-18.83$ & 18.84 & 10.0 & 6.2 \\
$17^{\prime}$ Heating during & $30^{\prime \prime}$ "Foen" & & & & \\
$18^{\prime}$ & -58.0 & $18.90-19.22$ & 19.06 & 9.5 & 6.8 \\
$21^{\prime}$ & +62.0 & $19.50-19.54$ & 19.52 & 11.5 & 16 \\
$24^{\prime}$ & -61.8 & $19.53-19.47$ & 19.50 & 11.4 & 18.8 \\
$27^{\prime}$ & +60.8 & $19.37-19.30$ & 19.34 & 11.0 & 11.3 \\
$30^{\prime}$ & -59.2 & $19.20-19.11$ & 19.15 & 10.0 & 15 \\
$36^{\prime}$ & -57.2 & $18.90-18.85$ & 18.88 & 9.3 & 13 \\
$39^{\prime}$ & +56.7 & $18.82-18.80$ & 18.81 & 9 & 13 \\
$42^{\prime}$ & -56.3 & $18.73-18.71$ & 18.72 & 9 & 8 \\
$45^{\prime}$ & -55.7 & $18.70-18.68$ & 18.69 & - & - \\
$48^{\prime}$ & +55.6 & $18.65-18.63$ & 18.64 & - & - \\
$51^{\prime}$ & -55.2 & $18.60-18.60$ & 18.60 & - & -
\end{tabular}

From the data of this experiment the mean temperature coefficient $\mathrm{t}^{1}$ has been found to be approximately $10 \%$ per degree (cf. Table I and the curve in Fig. 1-circles with crosses inside). This is an extraordinarily high value exceeding from three to five times the same coefficient for liquid conductors. After this, films were exposed to light. To protect them from heating by red and infra-red rays, bearing the greater part of the energy of the spectrum, the glass window of the box was covered with a cobalt glass, which absorbed these rays and allowed the most actinic blue and violet rays to pass.

${ }^{1}$ For this calculation changes of $\mathrm{N}$ and $\mathrm{T}^{\circ}$ from the initial state $(N=53.1$, $t^{\circ}=18.09^{\circ}$ ) to the respective reading were used. In the last column (U.t.c. of exp.) mean temperature coefficients are given calculated from changes of $\mathbf{N}$ and $t^{\circ}$ from one reading to the next one. This method, more sensitive than the first one, gives figures which depend in a high degree on the accidental inaccuracies of every reading. Therefore only the mean temp. coef. from the initial state are tabulated in further tables and represented graphically. 
Sun was taken as the source of light. Its rays were deflected by two mirrors into the box and fell upon the film. Readings on the thermometer and the galvanometer were made every 3 min., beginning a certain time before the exposure to light and continuing for some time after its action has ceased. The results of a typical experiment are given in Table II and the Fig. 2.

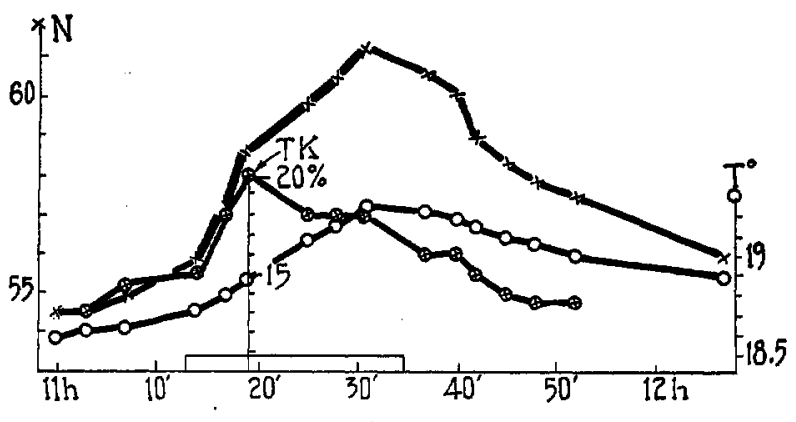

Fig. 2

TABLE II

28-IV 1917. Battery-200 el.

$\mathrm{C}=1 / 2 \mathrm{MF}$. High sensitivity

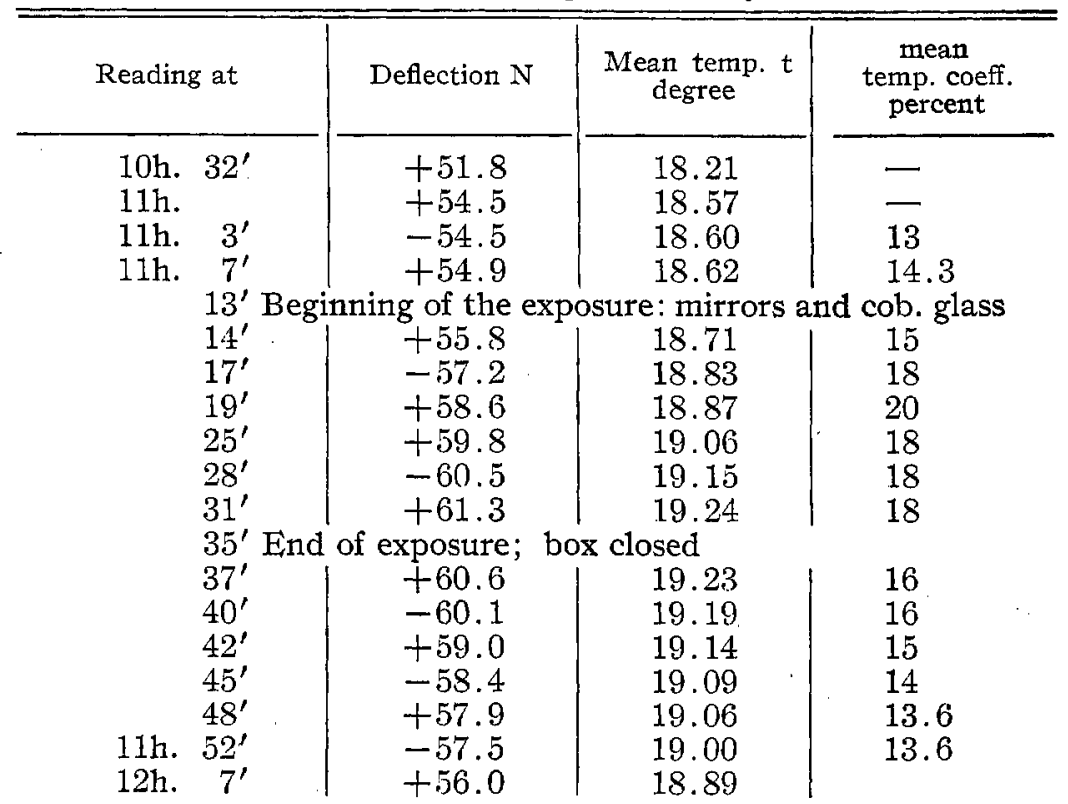


It can be seen from these data that the curve of galvanometer deflections (nearly proportional to the conductivity) rises, following closely the curve of temperature increase i. e., the same as in Fig. 1, where heating was not accompanied by the action of the light.

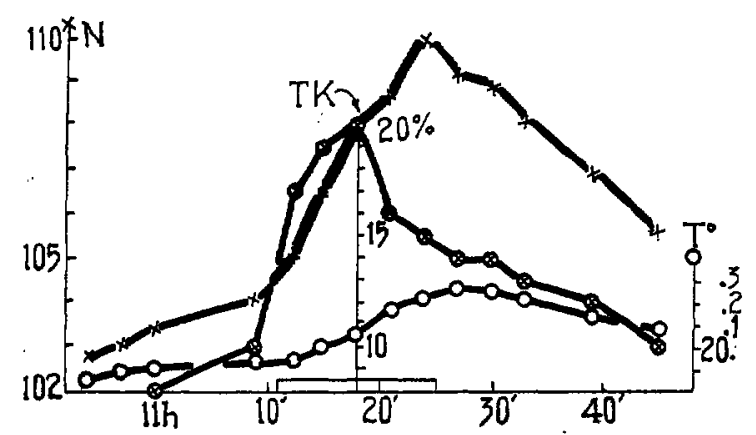

Fig. 3

TABLE III

12/V 1917. Same conditions as in Table II

\begin{tabular}{cc|c|c|c}
\hline \hline Reading at & Deflection $\mathrm{N}$ & $\begin{array}{c}\text { Mean temp. } \mathrm{t} \\
\text { degree }\end{array}$ & $\begin{array}{c}\text { Mean } \\
\text { temp. coeff. } \\
\text { percent }\end{array}$ \\
\hline 10h. & $48^{\prime}$ & +102.6 & 19.80 & - \\
& $54^{\prime}$ & +102.8 & 19.85 & - \\
& $57^{\prime}$ & -103.0 & 19.88 & - \\
$11 \mathrm{~h}$. & & +103.4 & 19.90 & 8 \\
& $9^{\prime}$ & -104.0 & 19.93 & 10
\end{tabular}

$11^{\prime}$ Beginning of the expos. to sun-light: mirrors and cob glass

\begin{tabular}{l|r|r|r}
$12.5^{\prime}$ & +105.0 & 19.94 & 17 \\
$15^{\prime}$ & -106.4 & 20.00 & 19 \\
$18^{\prime}$ & +107.9 & 20.06 & 20 \\
$21^{\prime}$ & -108.6 & 20.17 & 16 \\
$24^{\prime}$ & +110.0 & 20.22 & 15 \\
$25^{\prime}$ & End of exposure. & Box closed & \\
$27^{\prime}$ & -109.1 & 20.26 & 14 \\
$30^{\prime}$ & +108.9 & 20.25 & 14 \\
$33^{\prime}$ & -108.1 & 20.22 & 13 \\
$39^{\prime}$ & +106.9 & 20.14 & 12 \\
$45^{\prime}$ & -105.6 & 20.08 & 10
\end{tabular}


For comparison we give in the Table III and Fig. 3 the results of similar observations made over an exposed developed and fixed film, which is no longer light-sensitive.

The form of the curve is quite analogous to that in Fig. 2. Light-sensitiveness does not affect the conductivity. Table IV and Fig. 4 represent a similar experiment with a fresh un-

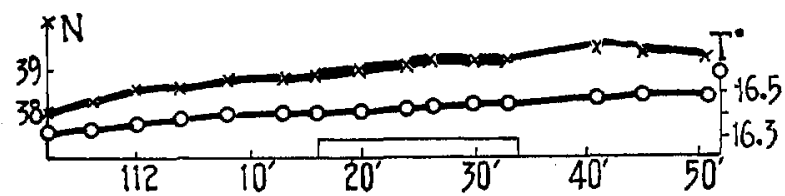

Fig. 4

exposed film with the only difference that the film received no direct sun-light, but diffused light from the clouds on a dull day.

TABLE IV

3/V, 1917. Same conditions. Diffused light

\begin{tabular}{|c|c|c|}
\hline Reading at & Deflection N & $\begin{array}{c}\text { Mean temp. } \mathrm{t} \\
\text { degree }\end{array}$ \\
\hline 10h. $52^{\prime}$ & +38.0 & 16.31 \\
\hline $56^{\prime}$ & -38.3 & 16.33 \\
\hline 11h. & +38.6 & 16.35 \\
\hline $4^{\prime}$ & -38.6 & 16.38 \\
\hline $8^{\prime}$ & +38.8 & 16.40 \\
\hline $13^{\prime}$ & -38.8 & 16.40 \\
\hline $.16^{\prime}$ & +38.9 & 16.40 \\
\hline \multicolumn{3}{|c|}{$\begin{array}{l}\text { Begin of the exposure. Mirror and cob. glass } \\
\text { Diffused light from clouds }\end{array}$} \\
\hline $20^{\prime}$ & -39.0 & 16.41 \\
\hline $24^{\prime}$ & +30.1 & 16.42 \\
\hline $26.5^{\prime}$ & -39.2 & 16.43 \\
\hline $30^{\prime}$ & +39.2 & 16.45 \\
\hline $33^{\prime}$ & -39.2 & 16.45 \\
\hline \multicolumn{3}{|c|}{ End of exposure, box closed } \\
\hline $41^{\prime}$ & +39.5 & 16.47 \\
\hline $45^{\prime}$ & -39.4 & 16.48 \\
\hline $51^{\prime}$ & +39.3 & 16.48 \\
\hline
\end{tabular}

Here the heating is insignificant, and the conductivity increase is very small. The action of light cannot be stated, 
as before. The same result has been obtained (the $30 / 17$ Apr. 1917) with an exposed and developed film on a very dull day. No heating took place-the temperature and conductivity were quite constant.

If we calculate the mean temperature coefficient (as described above and plot them in curves 1-3 (in these figures) the values of the mean temperature coefficient (T.C.) are designated by crosses in circles) we can see that when heating only is applied (without action of light) the changes of T.C. are small (see Table I and Fig. 1). If the film be exposed to light, the T.C. increase very rapidly (see Table II and Fig. 2), but decrease again after the action of light has ceased. These facts could be interpreted as a proof of an influence of light on conductivity. However, this is wrong, because the same phenomenon was observed when a developed and fixed film, which is no longer light-sensitive, was exposed to light (see Table III and Fig. 3). It follows from this that the observed action of light is of secondary origin; it is caused by the greater heating of the film, which absorbs the light, in comparison with the surrounding air and the thermometer, which notes its temperature changes. The observed effect is a bolometric one and is not connected with the light-sensitiveness of the film.

In the preceding tables the abnormally large values of the mean temp. coeff. of conductivity attract our attention. They amount in some instances to $20 \%$ never falling lower than $10 \%$ per degree. These abnormally high values depend possibly, on the separation of a part of the water from the sensitive layer (presenting a gel from the standpoint of colloidal chemistry) under the influence of heat, the gel being at higher temperatures in equilibrium with a smaller quantity of water.

To protect the film from the influence of humidity, it was covered (together with the contacts) with sandarac-benzenevarnish. After drying, the conductivity under the action of heating and light was measured. The temp. coeff. decreased to $5 \%$ per degree, the general form of the curve remaining the same as above. Only the increase of conductivity did not follow the heating so quickly and became not quite reversible 
(a phenomenon analogous to hysteresis). The conductivity of a varnished film is not affected by light.

As the determinations with dry films did not give the expected results, new experiments were undertaken with a liquid and a jelly-form emulsion, to facilitate the migration of electricity-bearers, if these would appear under the action of light. In preparing the emulsion I followed with insignificant modifications the prescription of Eder: ${ }^{1}$
A. $\mathrm{NH}_{4} \mathrm{Br}-2 \mathrm{gr}$, gelatine-2 gr, water $20 \mathrm{cc}$.
B. $\mathrm{AgNO}_{3}-3 \mathrm{gr}$, distilled water $12.5 \mathrm{cc}$.
C. Gelatine $2-5-\mathrm{gr}$, water $20 \mathrm{cc}$.

Solution B was poured into A under shaking, the liquid was boiled, poured into $\mathrm{C}$, and the whole stirred. After solidification the mass was pressed through a metal gauze and washed many hours in running water. All these operations were made in the dark or under faint red light.

The carefully washed emulsion was melted and introduced into an Arrhenius vessel for conductivity measurements. From outside it was covered with black asphalt-varnish except the lower part containing the emulsion and two platinum electrodes. The vessel was suspended on a flat metallic ring, to which a cylindrical metal screen could be pressed tightly from below by means of an india-rubber ring. When light had to act upon the emulsion, the screen slid down on special rails and opened the lower part of the vessel, which had not been blackened.

The conductivity of the emulsion was much larger than that of the dry layer-about $5 \cdot 10^{-4} \mathrm{ohm}^{-1} \mathrm{~cm}^{-1}$. All measurements could be made therefore by the well-known method of Kohlrausch-Ostwald-by means of alternating current, using a wire bridge and a telephone. The vessel was placed in an Ostwald thermostat with transparent glass walls. As the source of light, a Tungsram $1 / 2$ watt lamp of $400 \mathrm{HK}$ at a distance of $20 \mathrm{~cm}$ was used, or sun-light, reflected by means of a mirror.

${ }^{1}$ L. M. Eder: Ausf. Handbuch der Photographie, IIT, 216. 
The same facts were observed as in the dry layer; the emulsion was heated rapidly by light, and the change of conductivity was greater than could be expected from the temperature change, because the thermometer was immersed in the surrounding water of the thermostat, not in the emulsion itself. This made all temperature coefficients too large.

Table $\mathrm{V}$ and Fig. 5 represent the results of an experiment, when reflected sun-light fell on the emulsion.

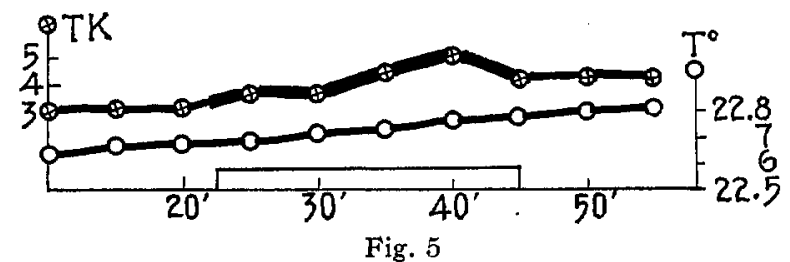

TABLE V

29/VII-1917. Kohlrausch's method

Liquid $\mathrm{AgBr}-$ gelatine emulsion

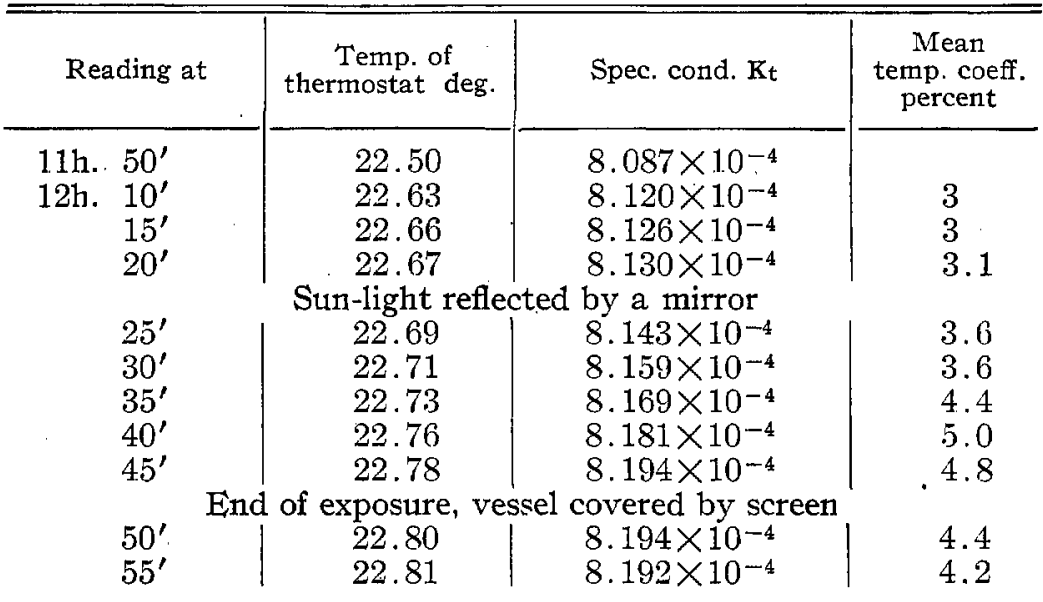

The mean temp. coef. increase twofold under these conditions. To prove the bolometric origin of this effect pure gelatine solution without $\mathrm{AgBr}$ was taken, but gave no result as absorbing too small a quantity of light. To increase the . absorption of light, an "emulsion" (rather, a suspension) of 
barium sulphate in gelatine was prepared where the conditions of light diffusion and absorption are the same as in the bromogelatine silver emulsion. This mixture showed under the action of light a similar (even a larger) increase of temp. coef. of conductivity, not being light-sensitive at all (see Table VI and Fig. 6). Here also the effect was found to be a bolometric one.

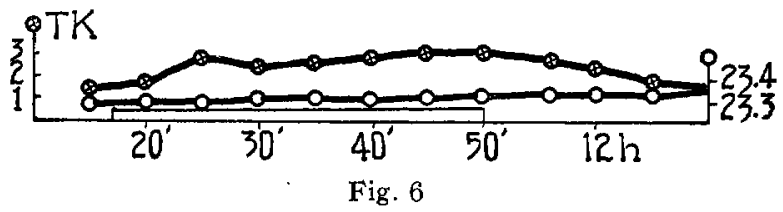

TABLE VI

(31-VIII, 1917) Kohlrausch's method Gelatine with suspended $\mathrm{BaSO}_{4}$

\begin{tabular}{|c|c|c|c|}
\hline Reading at & $\begin{array}{c}\text { Temp. of } \\
\text { thermostat } \\
\text { degree }\end{array}$ & Spec. cond. & $\begin{array}{c}\text { Mean } \\
\text { temp. coeff. } \\
\text { percent }\end{array}$ \\
\hline \multirow{9}{*}{$11 \mathrm{~h}}$. & $\begin{array}{l}23.23 \\
23.27\end{array}$ & $\begin{array}{l}3.602 \times 10^{-4} \\
3.604 \times 10^{-4}\end{array}$ & $\overline{1.4}$ \\
\hline & \multicolumn{2}{|c|}{ sun-light reflected by mirror } & \\
\hline & 23.28 & 3.605 & 1.7 \\
\hline & 23.28 & 3.607 & 2.8 \\
\hline & 23.30 & 3.608 & 2.4 \\
\hline & 23,30 & 3.608 & 2.6 \\
\hline & 23.30 & 3.609 & 2.9 \\
\hline & 23.31 & 3.611 & 3.1 \\
\hline & 23.32 & 3.612 & 3.1 \\
\hline \multicolumn{4}{|c|}{ End of exposure } \\
\hline $56^{\prime}$ & 23.32 & 3.611 & 2.8 \\
\hline \multirow{2}{*}{$12 \mathrm{~h}}$. & 23.33 & 3.610 & \\
\hline & 23.33 & 3.609 & \\
\hline $10^{\prime}$ & 23.35 & 3.609 & \\
\hline
\end{tabular}

Experiments with dry and liquid photographic emulsions showed that their electrical resistance does not change within the limits of experimental errors when they are exposed to light. The interest of this fact is especially great if we compare it with the stated change of resistance of pure halide silver salts under the action of light. It is probable that the same changes 
occur in the silver bromide of the photographic emulsion, but they cannot influence its general resistance as the propagation of these changes is paralysed by the gelatine surrounding the separate granules of $\mathrm{AgBr}$.

Therefore, the determinations of conductivity with the degree of accuracy now attainable do not give the possibility to follow those changes and to resolve the question about the nature of the latent image.

The subject of this paper was suggested to me by Prof. N. P. Kasterine, to whom I express my sincere thanks.

Physical Laboratory

Odessa University

IOI7 